\title{
A reconceptualização dos modos de produção de saúde no contexto da reforma hospitalar portuguesa
}

The Reconceptualisation of Modes of Healthcare Production within the Context of the Portuguese Hospital Reform

La reconceptualisation des modes de production de santé dans le contexte de la réforme hospitalière portugaise

\section{Tiago Correia}

\section{OpenEdition}

\section{Journals}

Edição electrónica

URL: http://journals.openedition.org/rccs/350

DOI: $10.4000 /$ rccs. 350

ISSN: 2182-7435

\section{Editora}

Centro de Estudos Sociais da Universidade de Coimbra

Edição impressa

Data de publição: 1 Junho 2009

Paginação: 83-103

ISSN: 0254-1106

Refêrencia eletrónica

Tiago Correia, «A reconceptualização dos modos de produção de saúde no contexto da reforma hospitalar portuguesa », Revista Crítica de Ciências Sociais [Online], 85| 2009, colocado online no dia 01 dezembro 2012, criado a 01 maio 2019. URL : http://journals.openedition.org/rccs/350 ; DOI : $10.4000 /$ rccs.350 


\section{TIAGO CORREIA}

\section{A reconceptualização dos modos de produção de saúde no contexto da reforma hospitalar portuguesa*}

Este artigo debruça-se sobre as recentes reformas desenvolvidas no sector hospitalar português. Trata-se da implementação de princípios da Nova Gestão Pública, não sendo, por isso, uma opção política exclusiva nem inovadora em Portugal.

Decorrente do processo de tendencial empresarialização dos hospitais públicos, elege-se como objectivo perceber em que medida estas reformas afectam o significado da prestação pública de cuidados. A abertura às regras de mercado e, consequentemente, a um contexto de concorrência entre os prestadores públicos e entre os prestadores públicos e privados associa a empresarialização à mercadorização da prestação pública de cuidados. Não estando em causa o fim de um modo de produção de saúde estatal, apresentam-se argumentos que parecem comprovar que estas reformas afectam conceptualmente o modo de produção de saúde estatal definido por Boaventura de Sousa Santos em 1987, esbatendo algumas das fronteiras em relação ao modo de produção de saúde capitalista.

Palavras-chave: modos de produção de saúde; mercadorização; empresarialização hospitalar; Nova Gestão Pública.

\section{Introdução}

Nos últimos anos tem-se assistido a significativas intervenções políticas no âmbito da administração pública em geral, com especial incidência no sector da saúde. Trata-se de uma tendência extensível à generalidade dos países europeus, já que resulta das contradições implícitas do modelo de Estado-Providência.

Estas intervenções políticas têm-se traduzido numa "Nova Gestão Pública” (NGP) ${ }^{1}$ dos serviços públicos. O objectivo é assegurar os interesses colectivos segundo princípios organizacionais de eficácia e de eficiência,

\footnotetext{
* Artigo inserido na investigação de Doutoramento em Sociologia financiada pela FCT.

1 Tradução do original em inglês "New Public Management" (ver Pollitt, 1990).
} 
outrora circunscritos à actividade empresarial privada. Por outras palavras, a solução para fazer face à incapacidade de se sustentar um modelo de prestação de serviços públicos como aquele que caracterizou a consolidação dos Estados-Providência após a $2^{\mathrm{a}}$ Guerra Mundial foi trazer para o domínio estatal lógicas de funcionamento do domínio privado capitalista. $\mathrm{Na}$ sua base, a concretização da NGP tem implícita a ideia de desperdício e de ineficiência do "tradicional" sector público e a ideia das qualidades de gestão do sector privado. Caso o bem público seja gerido como o bem privado, terá como resultado uma melhor gestão.

É inegável que a alteração da prestação de serviços públicos nos países europeus relativamente ao seu funcionamento de há 20 ou 30 anos decorre da incorporação de dinâmicas político-ideológicas mais liberais. Sobretudo por via do Reino Unido no tempo de Thatcher, foi legitimada a racionalização da actividade pública representando uma convergência em torno de políticas neoliberais.

Concretamente em Portugal, o presente momento de intervenção reformista não se circunscreve apenas a uma única base partidária, sendo uma tendência identificável, grosso modo, desde 2002 com o governo social-democrata de Durão Barroso. Embora 2002 possa, efectivamente, ser apontado como o momento em que a intervenção governamental assumiu maior intensidade e sistematicidade, com importantes marcos legislativos no sector da saúde, importa considerar que as mudanças na forma como o Estado disponibiliza os serviços públicos decorre de perspectivas políticas de finais dos anos 80 , por sua vez influenciadas por argumentos e justificações com origem ainda nos anos 60. Deste ponto de vista, a concretização da NGP no sector da saúde em Portugal não é um processo inovador.

Identificadas as dinâmicas políticas que servem de base à discussão que se apresenta, o objectivo deste artigo é problematizar em que medida a reconfiguração jurídico-legal do funcionamento dos hospitais públicos, ocorrida nos últimos anos, implica a reconfiguração do modelo que conceptualiza o modo de produção de saúde estatal definido em 1987 por Boaventura de Sousa Santos. Está em causa compreender até que ponto a conjugação entre o interesse público, outrora fundamental e exclusivo do modo de produção de saúde estatal, é alterado pelas actuais dinâmicas de empresarialização dos prestadores públicos. As consequências mais significativas da empresarialização prendem-se com a dotação de autonomia administrativa, financeira e patrimonial dos hospitais, ao mesmo tempo que a actividade hospitalar pública se exerce num contexto de crescente exposição às lógicas de mercado. Esta exposição a regras concorrenciais 
é entendida enquanto manifestação da mercadorização que Boaventura de Sousa Santos associou predominantemente ao modo de produção de saúde capitalista.

Esta discussão é desenvolvida apenas a nível jurídico e não em termos organizacionais. Não obstante um direccionismo político bastante acentuado quanto ao desempenho hospitalar esperado, nomeadamente sobre os resultados alcançados, não se pode pressupor que o funcionamento organizacional coincida contínua, clara e inequivocamente com os contornos gerais definidos em letra de lei. Carapinheiro (1993), seguindo teorias organizacionais discutidas por autores como Crozier e Friedberg (1977), Child (1973) ou Goss (1963), contribuiu com a primeira abordagem sociológica em Portugal sobre os hospitais, concluindo que o seu funcionamento organizacional decorre em grande parte das relações profissionais e das ordens negociadas que aí se estabelecem, não se assumindo como meros receptáculos da envolvente política. O que se pretende dizer é que, mesmo que as alterações organizacionais enquadradas pelas actuais reformas revelem concretizações várias e nem sempre coincidentes - conclusão apresentada por Carvalho (2005) num dos ainda raros estudos em Portugal sobre as consequências da NGP para o funcionamento hospitalar -, subsistem em todas elas uma ideologia managerialista de conteúdo amplo e algo vago. ${ }^{2}$

Desde já, importa considerar o hospital como principal elemento do sistema de saúde português, o que justifica que a sua revisão jurídico-normativa sirva de base para a discussão sobre os modos de produção de saúde que Boaventura de Sousa Santos definiu. ${ }^{3}$ Aliás, embora possa ser identificada uma preocupação política crescente com outros prestadores de cuidados além dos hospitais, caracterizando uma concepção integrada e diversificada de cuidados de saúde que envolve hospitais, centros de saúde e outros prestadores (e.g. OPSS, 2009; Correia, s.d.), o facto de as primeiras

\footnotetext{
${ }^{2}$ Carvalho (2005: 23) refere que na literatura portuguesa o termo managerialism tem sido traduzido como gerencialismo ou como managerialismo. Concorda-se com os argumentos apresentados pela autora quando opta pelo managerialismo, afirmando que entre os dois termos é "o que melhor circunscreve a complexa dimensão do conceito, permitindo-nos, simultaneamente, significar a sobreposição dos critérios de gestão aos critérios políticos de governação e manter a dignidade académica do termo gestão".

${ }^{3}$ Metodologicamente, a produção legislativa foi consultada através da edição electrónica do Diário da República (www.dre.pt), onde são disponibilizados todos os Diários da República desde a década de 60. A escolha dos documentos foi efectuada segundo um método bola de neve. Isto é, a partir da produção jurídica mais recente, procurou-se referências a documentos anteriores revogados ou ratificados. Neste artigo não se apresenta uma exposição exaustiva de toda a produção legislativa, mas apenas os elementos ilustrativos da discussão que se pretende desenvolver. Perante os resultados obtidos, considerou-se este como o método mais profícuo na organização da pesquisa. Foi analisada toda a produção legal em matéria da saúde, com especial relevância as reformas no sector hospitalar.
} 
intervenções políticas se centrarem quase em exclusivo no sector hospitalar permite que se continue a identificar o carácter "hospitalocêntrico" do sistema de saúde português referido por Correia de Campos (1984). ${ }^{4}$

Importa clarificar que a reconceptualização dos modos de produção de saúde que se considera necessária, em particular ao modo estatal, não os reduz ao sector hospitalar. Contudo, dada a importância desse sector no sistema de saúde em Portugal, as suas reformas, além de operadas em primeiro lugar, trarão consequências mais visíveis para o significado da prestação pública de cuidados.

Tendo em conta os objectivos apresentados, num primeiro momento define-se o significado do processo de empresarialização, bem como a sua concretização na saúde em Portugal. Inclui-se uma análise sobre as mudanças legislativas que têm ocorrido no sector hospitalar português nos últimos anos, especificamente, a mudança jurídica dos hospitais. Esta mudança foi no sentido da transformação do sector público administrativo (SPA) para as sociedades anónimas de capitais exclusivamente públicos (SA) numa primeira fase, e mais tarde para os estabelecimentos públicos empresariais (EPE). Posteriormente, procede-se a uma discussão sobre o modelo conceptual dos modos de produção de saúde proposto por Boaventura de Sousa Santos. Num último momento, apresentam-se então os argumentos que parecem justificar que as reformas no sector público hospitalar implicam uma reconceptualização do modo de produção de saúde estatal.

\section{O processo de empresarialização hospitalar e a sua concretização em Portugal}

A empresarialização hospitalar apresentou-se como a possibilidade de adequar a prestação pública de cuidados às necessidades financeiras sentidas, num contexto internacional de crises fiscais e de problemas orçamentais dos estados (Esping-Andersen, 1996; Ferrera et al., 2000; OPSS, 2009). Importa, desde já, esclarecer que a empresarialização desenvolvida em

\footnotetext{
${ }^{4}$ Carapinheiro (1993: 22) afirma que a orientação hospitalocêntrica que caracteriza o sistema de saúde português não está apenas enraizada nas práticas e representações da população, mas também nas práticas e representações dos profissionais envolvidos: "a cultura médica nacional é predominantemente associada à cultura do corpo médico hospitalar, acabando por serem omitidas as várias culturas profissionais dos médicos situados em zonas de acção e decisão não hospitalar”. Tal centralidade pode ser ilustrada através, por exemplo, dos recursos humanos afectos aos hospitais e centros de saúde. Segundo dados divulgados pela Direcção Geral de Saúde (2007), para o ano de 2006, enquanto nos centros de saúde estavam 26971 pessoas ao serviço entre médicos (7096), pessoal de enfermagem (7236), outro pessoal técnico superior (464), pessoal técnico (913) e outro pessoal (11262), nos hospitais contabilizavam-se 92214 pessoas ao serviço, entre médicos (16549), pessoal de enfermagem (30077), outro pessoal técnico superior (2688), pessoal técnico (16693), outro pessoal (26207).
} 
Portugal é em tudo semelhante àquilo que na literatura anglo-saxónica é descrito por corporatization. Assim sendo, a aposta neste modelo não é exclusiva a Portugal, nem tão pouco se trata de uma concepção recente, decorrendo dos princípios da "Nova Gestão Pública" desenvolvida em Inglaterra ainda na década de 80 (e.g. OECD, 1995; Gomes, 2001; Gruening, 2001; Bach e Kessler, 2007).

Apesar da empresarialização hospitalar representar a necessidade de racionalização dos gastos públicos, o que pode ser integrado num processo de liberalização da actividade estatal, opta-se por não se falar na "americanização dos sistemas de saúde europeus". Os sistemas de saúde europeus baseiam-se sobretudo nos contornos assumidos pelo exemplo inglês, esse sim permeável ao liberalismo, principalmente no tempo de Thatcher e Reagan (sobre as dinâmicas do neoliberalismo ver, por exemplo, Mechanic e Rochefort, 1996; Peck e Tickell, 2002). ${ }^{5}$ Deste ponto de vista, sob imperativos de ordem financeira, o último quartel do século Xx ficou marcado pelo fim do consenso sobre o Estado-Providência (Exworthy e Halford, 1999). A consensualidade de hoje é que o modo como a prestação pública de cuidados foi pensada e implementada no pós-2a Guerra Mundial tornou-se insustentável. Neste sentido, como (Beck, 2000: 71-72) refere:

[...] a perda de segurança característica do trabalho estandardizado do sistema fordista é bem aceite e politicamente acelerada, como se se tratasse de um processo natural [...]. É uma questão dos efeitos colaterais do modo americano, o qual se tornou o modelo para a modernização em todas as partes do mundo desde o fim do conflito Oriente-Ocidente.

Concretamente em Portugal, não obstante a existência legal de um estatuto jurídico hospitalar intitulado por Entidade Pública Empresarial (EPE), concebe-se a empresarialização hospitalar como processo de maior ampli-

\footnotetext{
${ }^{5}$ Deste ponto de vista, não é igualmente correcto considerar-se a "europeização do modelo americano". Apesar de manifestações de interesse reiteradas pelo actual Presidente Americano Barack Obama e por alguns senadores americanos de engrossar as políticas sociais asseguradas pelo Estado (OPSS, 2009: 17), a história recente dos EUA e os medos que o socialismo representou fazem com que se mantenham fortes resistências ideológicas, tanto na esfera política como na esfera social, quanto àquilo que se rotula como sendo socialismo. Mesmo num cenário em que políticas sociais fossem efectivamente implementadas, não se pode esperar que assumam uma configuração semelhante às políticas sociais características dos Estados-Providência europeus. Note-se que esta delimitação EUA/Europa não pode ser tomada sob um ponto de vista rígido. Não foi fortuita a referência a modelos de Estado-Providência nos países europeus, contrariamente à noção de um modelo de Estado-Providência unívoco. A respeito das diferentes concretizações dos Estados-Providência, veja-se autores como Esping-Anderson (1996), Ferrera (2000) ou Silva (2002).
} 
tude. Nestes termos, a empresarialização respeita aquilo que autores como Pollitt (1990) ou Traynor (1996) designam como uma ideologia managerialista, em que à gestão é conferida neutralidade - para não dizer superioridade - na condução de praticamente todas as esferas da sociedade. Se a emergência dos Estados-Providência significou a elevação de áreas científicas como a medicina, o reconhecimento dos problemas do modelo trouxe a elevação de outras áreas, como a gestão. ${ }^{6}$

A ideia fundamental é que todos os estatutos jurídicos dos hospitais públicos portugueses são influenciados, em graus variáveis, por dinâmicas inequívocas quanto ao aumento da autonomização das competências gestionárias e à centralidade conferida a instrumentos próprios do sector empresarial privado. Além disso, hoje em dia alterou-se a noção dos utilizadores dos serviços de saúde, assumindo a designação de consumidores. Nesta óptica, os consumidores detêm a sua quota-parte de responsabilidade na escolha e utilização eficiente dos serviços públicos, o que comprova que as reformas recentes no modelo de "bem-estar" estão orientadas para uma cidadania activa e para um envolvimento consciente dos utilizadores dos recursos públicos (Lister, 2001).

Segundo a Lei n. ${ }^{\circ} 27 / 2002$, que aprova o novo regime jurídico da gestão hospitalar, são definidas três figuras jurídicas para os hospitais públicos (além dos hospitais privados):

- Estabelecimentos públicos, dotados de personalidade jurídica, autonomia administrativa e financeira, com ou sem autonomia patrimonial;

- Estabelecimentos públicos, dotados de personalidade jurídica, autonomia administrativa, financeira e patrimonial e de natureza empresarial;

- Sociedades anónimas de capitais exclusivamente públicos.

O primeiro estatuto jurídico diz respeito aos hospitais vulgarmente conhecidos por hospitais públicos. São os hospitais pertencentes ao Sector Público Administrativo (SPA), considerado politicamente como "excessivamente dispendioso, rígido e burocratizado" (Resolução do Conselho de Ministros n. ${ }^{\circ}$ 124/2005). O segundo estatuto jurídico refere-se ao modelo empresarializado, ou seja, hospitais entidades públicas empresariais (EPE). O terceiro estatuto jurídico diz respeito a hospitais geridos enquanto sociedades anónimas (SA), de capitais exclusivamente públicos. Não obstante

\footnotetext{
${ }^{6}$ Esta afirmação não significa que o actual papel da gestão diminua o estatuto social e o papel da medicina nas organizações de saúde. Esse é um debate de grande complexidade que foge à discussão que aqui se apresenta.
} 
neste último modelo o Estado se assumir enquanto accionista dos hospitais, o facto de os capitais serem públicos torna o seu funcionamento organizacional em tudo semelhante ao modelo EPE.

Segundo argumentos apresentados por Correia (s.d.), esta alteração das preferências governativas, ora para o modelo SA, ora para o modelo EPE, não altera substantivamente os princípios de financiamento e de funcionamento dos hospitais públicos. ${ }^{7}$ Aliás, nesse texto vai-se mais longe e considera-se que, apesar de diferenças no ponto de vista da gestão patrimonial e de recursos humanos, os hospitais SPA convergem com os fundamentos dos outros dois estatutos hospitalares. É precisamente por este motivo que anteriormente foi referido ser necessária uma interpretação mais alargada do processo de empresarialização, não o encerrando num único estatuto jurídico.

A introdução de princípios da NGP no sector hospitalar público português, estendendo-se também à concepção do "tradicional" sector público administrativo, situa-se ao nível da descentralização de competências de gestão para o espaço das organizações. Aos Conselhos de Administração (CA) de cada hospital cabem, individual e autonomamente, a concepção, a implementação e o controlo da actividade hospitalar, passando a adquirir competências em matérias que anteriormente eram definidas pelas instâncias de regulação 'meso' - Administrações Regionais de Saúde (ARS). De facto, embora o sector público administrativo mantenha alguma dependência em relação ao papel das ARS, sobretudo na definição de matérias como a actividade contratualizada, os indicadores de desempenho e as políticas de recursos humanos para os hospitais da região administrativa, torna-se clara a convergência entre os três modelos jurídicos dos hospitais públicos quanto ao papel que os mecanismos de gestão representam para a actividade hospitalar.

A descentralização de competências do nível 'macro' e 'meso' para o nível 'micro' traduz-se num aumento das suas competências de gestão administrativa, financeira e patrimonial, quando antigamente as suas funções estavam sobretudo relacionadas com a execução de decisões tomadas por níveis superiores de tutela. A implementação de princípios de tipo empresarial no sistema de saúde português procurou inverter a orientação do funcionamento dos hospitais públicos, em que da dupla lógica, de gestão e de fiscalização, "de cima para baixo", se passa para um entendimento de que, mesmo mantendo a função de fiscalização centralizada no poder cen-

\footnotetext{
7 Texto ainda não publicado, intitulado "Finding the meanings and the origin of the corporatization process in Portuguese public hospitals". Pode ser consultado em http://www.correiat.blogspot.com/
} 
tral, a gestão hospitalar deve passar a estar circunscrita a cada hospital traduzindo um sistema de gestão de "baixo para cima".

Além da crescente descentralização de competências e de responsabilidades para o nível micro, a partilha de princípios da NGP entre os três modelos jurídicos manifesta-se também na necessidade de racionalização dos custos. Como Exworthy e Halford (1999) referem, sem que seja possível atestar uma quebra de legitimidade da ideologia médica, dado o actual panorama financeiro, os gastos associados à medicina têm de ser aprovados com base em evidências clínicas.

A racionalização dos gastos públicos em saúde implica ainda que o orçamento (no caso dos hospitais SPA), o capital estatutário (no caso dos hospitais EPE) ou o capital social (nos hospitais SA) sejam definidos em função da actividade hospitalar efectivamente realizada. Assim, o financiamento dos prestadores públicos vê-se alterado através da introdução dos contratos-programa. Em traços gerais, os contratos-programa relacionam o prestador e a tutela numa relação contratual. $O$ primeiro vê-se obrigado a cumprir metas quantitativas e qualitativas aí definidas e o segundo a transferir as verbas necessárias para a prossecução desses objectivos. Note-se que o financiamento dos hospitais para o ano seguinte depende do resultado alcançado no ano precedente. Uma não utilização das verbas contratualizadas implica uma redução no financiamento do hospital no ano seguinte.

Embora a empresarialização em Portugal tenha sido associada à Lei n. ${ }^{\circ} 27 / 2002$, este é um processo anterior e já enraizado no domínio político em Portugal. A lei n. ${ }^{\circ}$ 27/2002 correspondeu ao momento em que as influências passadas da empresarialização foram concretizadas plenamente (através da transformação de 31 hospitais SPA em SA), além dos exemplos piloto como o caso do Hospital de S. Sebastião ou a Unidade Local de Saúde de Matosinhos (OPSS, 2009).

Noutro texto (Correia, s.d.) foi procurada a origem do processo de empresarialização em Portugal, tendo sido apresentado o ano de 1988 como o primeiro marco legislativo das reformas na saúde em Portugal. Aquando do XI Governo Constitucional social-democrata, com Aníbal Cavaco Silva como Primeiro-Ministro e Leonor Beleza como Ministra da Saúde, são legislados o decreto-lei n. ${ }^{\circ}$ 19/88, que aprova a lei da gestão hospitalar, e o decreto regulamentar n. ${ }^{\circ}$ 3/88. O Decreto-Lei n. ${ }^{\circ}$ 19/88 aponta para os argumentos que mais tarde foram aprofundados, nomeadamente na Lei n. ${ }^{\circ} 27 / 2002$, por considerar necessário o carácter empresarial dos hospitais, com todas as implicações que isso envolve. Esse documento surge como o primeiro indicador de abertura da actividade de prestadores públicos de cuidados de saúde aos paradigmas gestionários, introduzindo o que até 
então se consideravam mecanismos inovadores de gestão. Além disso, e uma vez mais, destaca-se esta necessidade pelo peso financeiro dos hospitais na prestação pública de cuidados:

Dentro da afirmação, hoje pacífica, de que a evolução do sistema hospitalar aponta claramente no sentido de uma dinâmica própria, a que subjaz uma unidade muito complexa onde se produzem bens e serviços, a sua gestão tem necessariamente de assentar em suportes compatíveis e que de forma alguma podem coincidir ou identificar-se com a situação relativamente bloqueante, como continua ainda a ser a actual, de um serviço público que, se não em teoria, pelo menos na prática, alinha a par dos que vivem integrados na gestão directa do Estado. E é aquela dinâmica, coerentemente suportada por toda uma estrutura interna que não esqueça princípios de natureza empresarial e claramente assente na iniludível integração da actividade hospitalar na economia do país, que impõe de forma rectilínea a assimilação, por parte do hospital, de uma boa parte das regras de gestão desconhecidas, por delas não carecerem, dos serviços públicos clássicos. (Decreto-Lei n. ${ }^{\circ}$ 19/88: 248-20)

Embora este possa ser apresentado como o marco inicial das reformas no sector hospitalar português, insere-se já num contínuo de orientações políticas com início encontrado ainda na década de 60. Do ponto de vista teórico, esta tendência comprova as conclusões reiteradas por Carapinheiro e Page (2001), que as políticas públicas em Portugal têm seguido uma continuidade estrutural. Carapinheiro acaba por concluir que, não obstante a ideia de alteração da acção do Estado na prestação de cuidados por via das reformas em curso, estes últimos anos consolidaram a "ideia dos tempos políticos na construção do sistema de saúde português, tal como hoje o conhecemos, mas sem que esta ideia [fique] vinculada ao propósito de propor uma periodização estritamente política" (Carapinheiro, 2006: 137).

Ilustrando estes argumentos, apresenta-se um olhar sobre os Orçamentos do Estado a partir de 2002. Anteriormente foi referido que a empresarialização deve ser compreendida enquanto processo de sentido amplo; veja-se agora como essas mudanças se expressam nas contas públicas. No Gráfico 1 é possível identificar no Orçamento do Estado para os anos 2003 e 2006 (elaborados respectivamente em 2002 e 2005) acréscimos significativos de despesa consolidada orçamentada para o Ministério da Saúde, tanto em termos da percentagem do PIB, como da percentagem de despesa da Administração Central. Em 2002, com o governo de Durão Barroso, procedeu-se à alteração do regime jurídico dos hospitais SPA para SA, o que envolveu a constituição dos respectivos capitais sociais. Esta alteração impulsionou um acréscimo de $13,8 \%$ da despesa na Administração Central para 15,4\%, e 

(2002-2009)

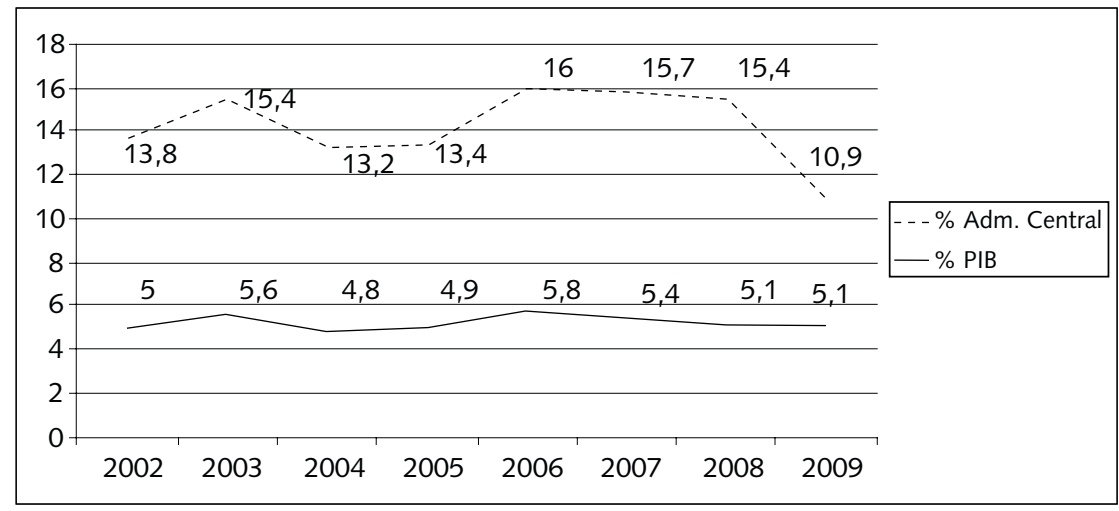

Fonte: OE 2002, 2003, 2004, 2005, 2006, 2007, 2008, 2009

de 5\% para 5,6\% do PIB. Em 2006, o governo de maioria socialista chefiado por José Sócrates substituiu os hospitais SA por hospitais EPE, ao que associou o aumento do número de hospitais SPA transformados em EPE. Esta dupla dinâmica voltou a justificar aumentos significativos em ambos os indicadores, passando o peso da despesa da Administração Central de 13,4\% em 2005 para 16\%, e o peso do Ministério da Saúde (MS) no PIB de $4,9 \%$ em 2005 para 5,8\% em 2006. Como é possível observar, as verbas destinadas ao MS entre 2006 e 2008 permaneceram num valor algo elevado comparativamente a 2002, o que encontra resposta na dinâmica de alteração dos hospitais SPA por hospitais EPE (e.g. Decretos-Lei n. ${ }^{\circ s} 27 / 2009$, 203/2008, 180/2008, 23/2008, 326/2007, 50-A/2007, 233/2005).

Como se pode observar, os dados apresentados na Tabela 1 mostram o peso dos hospitais públicos empresarializados, tendência que tem vindo a aumentar nos últimos anos. Em 2008, o estatuto jurídico EPE englobava praticamente $60 \%$ dos prestadores. A empresarialização ocorre até agora desproporcionalmente nos hospitais integrados em Centros Hospitalares ( $76 \%$ dos hospitais em centros hospitalares). ${ }^{8}$

\footnotetext{
${ }^{8}$ A figura jurídica dos centros hospitalares respeita uma concepção da organização dos prestadores hospitalares já defendida no decorrer dos anos 90. Mostrou-se a possibilidade de racionalizar e reestruturar as valências dos hospitais, dotando o nível micro com maiores competências de gestão para um conjunto de hospitais (integrados no respectivo centro hospitalar), geralmente organizados por proximidade geográfica. O conselho de administração define as valências e a afectação de recursos humanos entre o centro hospitalar.
} 
TABELA 1 - Contabilização dos prestadores hospitalares em Portugal Continental (2008) ${ }^{9}$

\begin{tabular}{|c|c|c|c|}
\hline \multicolumn{4}{|l|}{ Prestadores hospitalares } \\
\hline & SPA & EPE & Total \\
\hline Hospitais & 28 & 15 & 43 \\
\hline Hospitais incluídos em Centros Hospitalares & 14 & 45 & 59 \\
\hline Total & 42 & 60 & 102 \\
\hline
\end{tabular}

Fonte: Ministério da Saúde

Do ponto de vista das transferências para o SNS, o Gráfico 2 permite quantificar a dinâmica da empresarialização demonstrada anteriormente. O gráfico apresenta os montantes orçamentados para o Sistema Nacional de Saúde (SNS) de 2002 a 2009. Aquilo que se observa é uma progressiva repartição, que em 2009 chega a ser praticamente metade, de verbas para o sector "não SPA", isto é, para os hospitais SA, EPE e para as parcerias público-privadas. É ainda constatável que, se de 2002 a 2004 houve uma diminuição bruta nos montantes transferidos para o SNS, a partir de 2005 esse valor tem variado entre os 7.000 e 8.000 milhões de euros.

GRÁFICO 2 - Evolução dos gastos orçamentados para o SNS (2002-2009) (valores em milhões de euros)

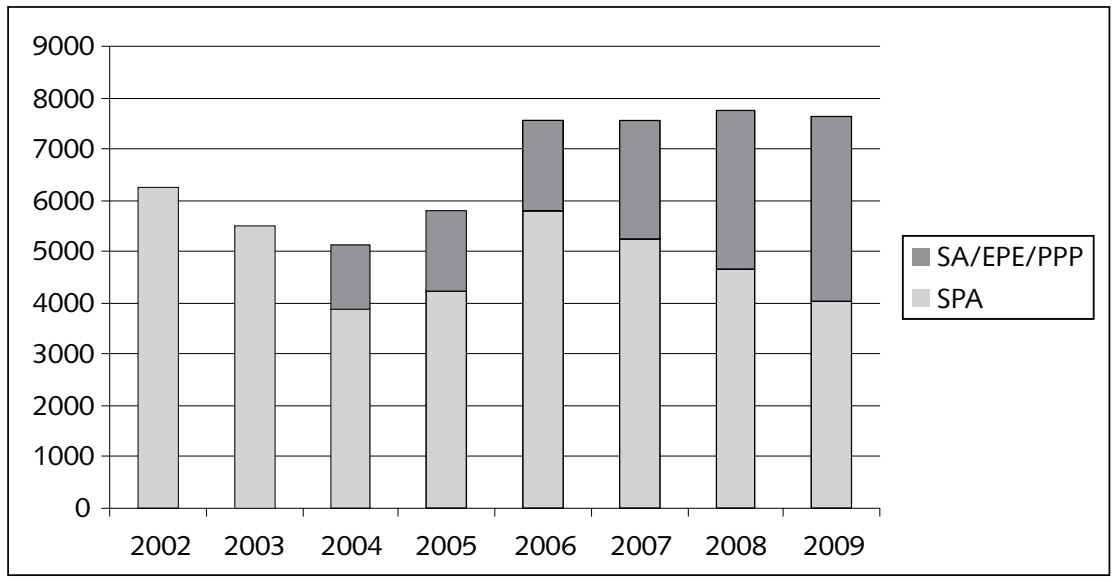

Fonte: OE 2002, 2003, 2004, 2005, 2006, 2007, 2008, 2009

\footnotetext{
${ }^{9}$ Esta análise reporta-se apenas ao território continental devido às especificidades da gestão dos prestadores hospitalares nas regiões autónomas. Com efeito, embora os estatutos jurídicos aplicados nestes hospitais assumam a mesma designação, vigora um documento legislativo de âmbito regional que define os estatutos dos Serviços Regionais de Saúde da Madeira e dos Açores, criando especificidades na prestação, regulação e financiamento dos cuidados (vide Decreto Legislativo Regional n. ${ }^{\circ}$ 4/2003/M para a Região Autónoma da Madeira e Decreto Legislativo Regional n. ${ }^{\circ}$ 2/2007/A).
} 


\section{Modos de produção de saúde: a utilidade do modelo conceptual}

O progressivo aumento dos hospitais empresarializados na rede hospitalar pública portuguesa, a par da reconfiguração do próprio sector público administrativo, servem de base à discussão sobre a prestação pública de cuidados, nomeadamente as consequências que tais mudanças representam no significado que a componente 'pública' pode adquirir. A questão a equacionar é que, perante a reconfiguração dos hospitais públicos portugueses, fica por se saber como definir a prestação pública de cuidados. Dado que os prestadores nos últimos anos têm vindo a ser sucessivamente alvo de mudanças, para onde progride a prestação pública de cuidados em Portugal?

Em 1987, Boaventura de Sousa Santos define três modos de produção de saúde presentes na sociedade portuguesa: o modo estatal, o modo privado e o modo artesanal. Enquanto o primeiro compreende a produção de saúde, total ou parcialmente desmercadorizada, através de prestadores públicos, o segundo é resultante da sociedade civil, inscrevendo-se nas regras de mercado. O modo de produção artesanal, por sua vez, é situando num nível conceptual mais distante, ainda que complementar dos anteriores, afastando-se por isso dos objectivos desta discussão. ${ }^{10}$

Compreendem-se os modos de produção de saúde enquanto tipos ideais. Representam, por isso, abstracções da realidade e não a realidade em si, pelo que a sua aplicação nos diferentes contextos sociais não impede que apresentem articulações e relações mútuas. Isto significa que os modos de produção de saúde, enquanto instrumentos conceptuais de análise, são definidos num plano de elevada abstracção, exacerbando-se assim as suas fronteiras, mas não esperando que a sua aplicação empírica revele essa clareza e demarcação teóricas. Pelo contrário, Santos (1987) considera que a realidade portuguesa é caracterizada por uma complexa configuração de modos de produção de saúde, sobretudo na ainda expressiva, mas em declínio, sociedade rural.

Apesar de uma aparente simplicidade no modo como se estabelece a relação entre a acção pública e a acção privada, em que teoricamente ao Estado cabe assegurar necessidades sociais, enquanto os privados actuam tendo em vista a prossecução do lucro, a actividade pública não pode ser reduzida ao Estado. O bem público tanto se assegura pelo Estado, como por intervenientes privados e da própria sociedade civil (Mozzicafreddo,

\footnotetext{
${ }_{10}$ A medicina popular emergindo, tal como a medicina privada, da sociedade civil, não adquire o mesmo grau de reconhecimento pela medicina estatal. Santos (ibid.: 66) define-a como uma medicina "que, não sendo estatal, é total ou parcialmente desmercadorizada ou que, sendo privada e produzida na sociedade civil, é de produção livre ou artesanal”, não se inserindo nas lógicas concorrenciais do mercado.
} 
2002). Aliás, a dupla retracção do Estado em Portugal, qualitativa e quantitativa, referida por Santos $(1987,1992)$ e que o leva a definir o Estado-Providência português como um "semi Estado-Providência", conduz a que a articulação público-privada seja incontornável. Quer isto dizer que a necessidade da presença de intervenientes além do Estado na prestação de serviços públicos, decorrente do actual contexto de necessidade de racionalização dos gastos públicos, pode justificar que nos diversos Serviços Nacionais de Saúde (SNS) se introduzam algumas tendências de pendor mais liberal (e.g. aumentos qualitativos e quantitativos dos prestadores privados, aumento da população coberta por seguros de saúde privados, concorrência entre prestadores públicos e privados).

Como se apreende, a principal consequência deste contexto generalizado aos países europeus é o crescente espaço de acção permitido aos agentes privados para a concretização de bens ou serviços públicos. Neste sentido, em graus variáveis, a actividade pública passa por prestadores privados.

Embora estes sectores sejam assumidos como interdependentes, o público e o privado mantêm uma diferença fundamental: o interesse com que desenvolvem a sua actividade. Enquanto o primeiro actua à luz de princípios de interesse comum, democratizando o acesso a cuidados de saúde e permitindo a salvaguarda de direitos sociais que foram sendo adquiridos, a actuação do segundo rege-se por via da sua racionalidade individual enquanto agente económico.

É necessário ter em conta que o facto de se dizer que a actuação pública se processa em torno da salvaguarda de interesses comuns não define o que se entende por interesse comum. Esse é um princípio orientador da acção política envolto numa elevada abstracção e variabilidade. Por outro lado, o facto de se afirmar que os prestadores privados prestam serviços públicos não contraria o argumento que estes prestadores baseiam a sua actividade com base no lucro - e que representa a garantia da continuidade da sua actividade. Essa prestação realiza-se mediante uma relação contratual com o Estado, necessariamente vantajosa em relação aos investimentos realizados para que privados prestem esse bem ou serviço. Como facilmente se depreende, o lucro decorrente da actividade é fundamental para a continuidade da prestação de cuidados. A quem disponibiliza, como disponibiliza e o que disponibiliza em termos da produção de saúde não se encontra ideológica nem necessariamente dependente de um qualquer interesse comum e público, mas antes da visão empresarial e da estratégia definida pelos responsáveis que financiam essa actividade.

Além do interesse subjacente à prestação da actividade, outra diferença entre os modos de produção de saúde diz respeito ao grau de exposição da 
prestação de cuidados às regras concorrenciais de mercado. Se, por um lado, o modo estatal de produção de saúde é definido como total ou parcialmente desmercadorizado, o que se justifica pelo facto de a sua prestação ser assegurada pelo Estado ou por entidades públicas dele dependentes, e por uma regulação laboral do sector que permite atenuar a concorrência entre o sector público e o sector privado, por outro lado, o modo de produção de saúde capitalista, assegurado por agentes privados, tem como característica elementar a sujeição às regras de mercado, caracterizando-se portanto como uma actividade parcial ou totalmente mercadorizada.

Perante isto, sabendo que a definição dos modos de produção de saúde serve para enquadrar a deambulação teórica sobre a prestação de cuidados de saúde, o que se procura demonstrar é que o contexto político que esteve na base da conceptualização de Boaventura de Sousa Santos sofreu alterações substantivas de tal ordem que atingiram o nível de abstracção em que se situam os modos de produção de saúde.

\section{As implicações da empresarialização hospitalar na concepção pública de cuidados de saúde}

O processo de empresarialização hospitalar, tal qual foi anteriormente definido, apresenta uma elevada complexidade, na medida em que parece compatibilizar elementos outrora exclusivos do modo de produção de saúde estatal e do modo de produção de saúde capitalista. Mais concretamente, a empresarialização hospitalar veio introduzir a mercadorização na prestação pública de cuidados, identificada através da uniformização do funcionamento do sector público em relação ao direito privado. Por outras palavras, o entusiasmo associado ao processo de empresarialização hospitalar, enquanto concretização dos princípios da NGP no sector da saúde, tem-se operado por via da actuação do sector público com base nas regras concorrenciais de mercado, tal como as empresas privadas. Esta convergência é inequívoca, como comprova o Decreto-Lei n. ${ }^{\circ}$ 558/99, definindo-se como uma orientação presente no direito comunitário:

as tendências de fundo neste domínio afirmam uma sujeição da generalidade das empresas públicas às normas de concorrência e a necessidade de afastar quaisquer distorções da concorrência especialmente emergentes do conteúdo e forma das relações entre o Estado e outros entes públicos e as empresas públicas que controlam. (9013)

Importa relembrar que a empresarialização foi definida enquanto processo de significado amplo, incluindo todas as figuras jurídicas dos hospitais públicos (SPA, SA e EPE). Analisando as consequências decorrentes da 
prestação pública de cuidados num contexto de mercadorização da actividade, destacam-se os contributos de Stoleroff e Correia (2008). Os autores debruçaram-se especificamente sobre a desregulação do mercado de trabalho, ou seja, as consequências que a individualização dos vínculos de trabalho representam para o sector público. Uma das conclusões apresentadas é que o sector hospitalar público tem sido caracterizado por significativos vazios de regulação do mercado de trabalho, sobretudo no caso dos médicos. A situação destes profissionais em concreto, devido à situação específica de escassez dos seus saberes em relação às necessidades sentidas, mostra como os hospitais do sector público acabam por concorrer entre si na captação dos recursos humanos, mas também concorrem com o sector privado numa lógica sem precedentes no SNS português. O que tem vindo a acontecer é a tendencial falta de regulação do emprego, em que o caso médico é paradigmático. Esta realidade recente tem significado processos individuais de negociação dos contratos de trabalho e, consequentemente, de escolha da entidade empregadora que melhor satisfaça os interesses pessoais. A detenção de saberes médicos constitui assim o principal elemento de mercadorização da prestação pública de cuidados, dotando estes profissionais de capacidade para negociação das suas condições de trabalho. De facto, não obstante a individualização das relações laborais existir para os restantes profissionais nos hospitais, a especificidade da medicina traduz-se numa situação de maior complexidade para a capacidade de contratação no sector público. Na medida em que cada hospital adquire autonomia de gestão, os respectivos Conselhos de Administração definem as suas políticas de recursos humanos e as condições de trabalho em função da sua capacidade orçamental.

Abre-se assim uma situação de potencial concorrência entre os hospitais públicos e entre hospitais públicos e privados. Anteriormente, com o vínculo de emprego público, numa lógica de carreira profissional, estavam uniformemente traçadas as condições de trabalho e as remunerações de cada categoria profissional. Presentemente, a introdução dos contratos individuais de trabalho desfaz esta uniformização e deixa que o funcionamento do mercado de emprego diferencie o valor de cada trabalhador. Deste ponto de vista, num contexto em que o mercado de emprego se apresenta de algum modo desregulado, em que a modalidade de contratação de profissionais para o sector público é a mesma que para o sector privado, nada impede que ambos os sectores se cruzem e se influenciem na definição do valor do trabalho e dos profissionais no mercado de trabalho.

Este exemplo da desregulação do mercado de trabalho, enquanto dinâmica de mercadorização da prestação pública de cuidados, não existia há 
20 anos, quando Boaventura de Sousa Santos definiu os modos de produção de saúde. A mercadorização assim problematizada salienta a importância crescente conferida ao factor capital no sector público, cruzando-o e incorporando-o no interesse público. Os governos vêm assim defendendo a compatibilização dos dois princípios, considerando que a correcta satisfação das necessidades colectivas em matéria de saúde pode ser eficaz e eficientemente garantida através da presença de outras entidades que não as públicas, além de que a exposição às regras da concorrência trará maiores benefícios à prestação pública de cuidados.

Mas a questão fundamental não é tanto os problemas que decorrem da presença de agentes públicos e/ou privados na prestação de cuidados e se essa presença se processa de forma mais ou menos articulada. Isso não afecta em nada o modelo conceptual que define o modo de produção de saúde estatal. O que está em causa é a concepção em que a produção de saúde estatal se suporta. Na evolução da legislação apresentada encontram-se dimensões que representam a incorporação de princípios decorrentes da gestão privada, logo, a legitimação para a incorporação do lucro e do 'capital'. Aspectos como uma utilização racional e eficiente dos recursos, a celebração de contratos-programa, a quantificação do desempenho nos mais diversos indicadores, ou a possibilidade de gerar receitas através da alienação de bens próprios e de rendimentos de bens próprios, são prosseguidos para um melhor funcionamento dos hospitais públicos portugueses. Ora, o simples facto de a concepção de eficiência estar inscrita nestes hospitais pode, à partida, revelar uma diferença substantiva dos objectivos que suportam a prestação de cuidados.

Neste contexto, pode surgir a dúvida de se o enraizamento das características do sector privado na prestação pública de cuidados permite que se continue a considerar um modo de produção de saúde estatal. Conceptualmente não está, de facto, em perspectiva o fim de uma vertente estatal da produção de saúde. Olhando para a definição inicial de Boaventura de Sousa Santos, continua a subsistir uma distância conceptual entre este modo de produção de saúde e o privado: a natureza do prestador. Enquanto no modo de produção de saúde estatal, independentemente dos seus contornos, a prestação de cuidados é pública e isso implica que se prossiga um interesse público na sua implementação, no modo de produção de saúde capitalista não se pressupõe que a actividade de prestação de saúde envolva esses princípios, ainda que não tenham que estar necessariamente excluídos.

Em termos conceptuais, estas distâncias não são negligenciáveis, representando diferentes concepções dos objectivos que estão por detrás da 
produção de cuidados. A discussão deve por isso centrar-se em saber quais serão as implicações da conjugação da mercadorização da saúde pública com o interesse público. De facto, a retracção qualitativa do Estado no sector, com a consequente abertura às lógicas de mercado, reconfigura profundamente os princípios dessa produção de cuidados.

Sistematizando o que foi apresentado, a introdução no sector público de aspectos decorrentes das lógicas empresariais e uma situação concorrencial pela captação dos recursos humanos, dimensões incluídas no modo de produção de saúde capitalista, alteram os significados da prestação pública de cuidados hospitalares. Com efeito, estas alterações revelam que o actual panorama da prestação pública de cuidados difere em relação àquele em que Boaventura de Sousa Santos se baseou quando em 1987 avançou com uma delimitação dos modos de produção de saúde.

Segundo a sua proposta, o modo de produção de saúde estatal seria assegurado por prestadores públicos, segundo uma actividade total ou parcialmente liberta da mercadorização. A partir da análise efectuada no plano legal foi possível constatar que, tanto nos hospitais EPE como nos hospitais do SPA (dado que actualmente não existem hospitais SA), coexistem lógicas de outros modos de produção de saúde que não o estatal. Assim, embora este tipo ideal contemple uma desmercadorização parcial da produção de cuidados, o argumento aqui defendido é a crescente e significativa mercadorização de toda a actividade hospitalar pública. Trata-se de uma mercadorização transversal a todos os modelos jurídicos e não característica de um ou outro modelo.

Em suma, repensando a definição de Santos, perante o que tem sido a experiência do processo de empresarialização em Portugal, por modo de produção de saúde estatal entende-se toda a actividade de prestação de cuidados disponibilizada por agentes públicos, num quadro de parcial ou total mercadorização dessa actividade.

\section{Conclusões e pistas de investigação}

A ideia principal discutida neste artigo é que o processo crescente de empresarialização hospitalar do sector público, por via da descentralização de competências para o nível micro, sendo os Conselhos de Administração de cada hospital as instâncias centrais de condução da respectiva actividade organizacional, implica um processo de mercadorização da actividade pública. Comprovou-se que, hoje em dia, a prestação pública de bens e serviços, e não apenas a prestação de cuidados hospitalares, se processa incluindo no seu funcionamento princípios do direito privado. Por conseguinte, a concorrência e a competitividade passam a estar associadas à 
prossecução do interesse público, reconfigurando o tipo ideal de modo de produção de saúde estatal.

Este é um processo em pleno desenvolvimento político. Neste sentido, não é possível prever em que moldes a prestação pública de cuidados irá assentar no futuro. Ainda assim, dado que este processo não é inovador em Portugal, decorrendo de influências identificadas ainda nos anos 80 , nem tão pouco exclusivo, já que resulta da transposição de dinâmicas europeias (que constituem aquilo que se definiu por Nova Gestão Pública), as experiências concretizadas sobretudo nos últimos anos deixam antever uma legitimação da mercadorização na actividade estatal. Este é um momento em que, perante as limitações e contradições do modelo social, entre os países europeus se aposta num funcionamento público "managerializado", isto é, gerido segundo os moldes dos bens privados.

Importa concluir distinguindo a empresarialização da privatização. Conceptualmente não está em causa o fim da vertente estatal da produção de saúde, mas antes a sua reconfiguração. Olhando para a definição inicial de Boaventura de Sousa Santos, continua a subsistir uma distância analítica entre este modo de produção de saúde e o privado: a natureza do prestador. A questão está em saber quais as implicações decorrentes para a prestação de cuidados de saúde e para o próprio SNS, devido à conjugação da mercadorização com o interesse público.

Percebendo que o esbatimento das fronteiras jurídico-normativas entre a produção pública e privada de cuidados não conduz ao fim de um modo público de produção de saúde, a retracção quantitativa e qualitativa do Estado no sector, com a consequente abertura às lógicas de mercado, reconfigura profundamente os princípios dessa produção de cuidados.

\section{Referências bibliográficas}

Assembleia da República (2002), “Lei n. ${ }^{\circ}$ 27/2002”, Diário da República, n. ${ }^{\circ}$ 258, Série I-A, 7150-4.

Assembleia Legislativa Regional da Região Autónoma da Madeira (2003), "Decreto

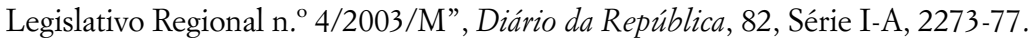

Assembleia Legislativa Regional da Região Autónoma dos Açores (2007), "Decreto Legislativo Regional n. 2/2007/A”, Diário da República, 17, Série I, 642-665.

Bach, Stephen; Kessler, Ian (2007), "Human Resource Management and the New Public Management”, in Peter Boxall, John Purcell e Patrick Wright (orgs.), The Oxford Handbook of Human Resource Management. Oxford: Oxford University Press, 469-488. Beck, Ulrich (2000), The Brave New World of Work. Trad. de Patrick Camiller. Cambridge: Polity Press. 
Campos, António Correia de (1984), Os hospitais no sistema de saúde português. Lisboa: Editora Portuguesa de Livros Técnicos e Científicos.

Carapinheiro, Graça (1993), Saberes e poderes no hospital: Uma sociologia dos serviços hospitalares. Porto: Afrontamento.

Carapinheiro, Graça (2006), “A Saúde enquanto matéria política”, in Graça Carapinheiro (org.), Sociologia da Saúde: estudos e perspectivas. Coimbra: Pé de Página, 137-164.

Carapinheiro, Graça; Page, Paula (2001), "As determinantes globais do sistema de saúde português”, in Graça Carapinheiro e Pedro Hespanha (orgs.), Risco Social e Incerteza: Pode o Estado Social recuar mais? Porto: Afrontamento, 81-122.

Carvalho, Maria (2005), Nova Gestão Pública e reformas da saúde: O profissionalismo numa encruzilhada. Aveiro: Universidade de Aveiro (Tese de Doutoramento).

Child, John (1973), "Organizational Structure, Environment and Performance: The Role of Strategic Choice”, in Graeme Salaman e Kenneth Thompson (orgs.), People and Organizations. London: Longman/Open University Press.

Correia, Tiago (s.d.), "Finding the meanings and the origin of the corporatization process in Portuguese public hospitals", artigo científico acessível em http://www.correiat. blogspot.com/.

Crozier, Michel; Friedberg, Erhard (1977), L'acteur et le Système: les contraintes de l'action collective. Paris: Éditions du Seuil.

DGS (2007), Centros de Saúde e Hospitais. Recursos e produção do SNS 2006. Lisboa: Direcção Geral de Saúde.

Esping-Anderson, Gøsta (1996), Welfare States in Transition. London: Sage.

Exworthy, Mark; Halford, Susan (1999), "Professionals and managers in a changing public sector: Conflict, compromise and collaboration?", in Mark Exworthy e Susan Halford (orgs.), Professionals and the New Managerialism in the Public Sector. Buckingham: Open University Press, 1-18.

Ferrera, Maurizio et al. (2000), O futuro da Europa social: repensar o trabalho e a protecção social na nova economia. Lisboa: Celta.

Ferrera, Maurizio (2000), "A reconstrução do Estado social na Europa Meridional”, Análise Social, 151-152, 457-475.

Gomes, João Salis (2001), "Perspectivas da Moderna Gestão Pública em Portugal", in Juan Mozzicafreddo e João Salis Gomes (orgs.), Administração e Política. Perspectivas de Reforma da Administração Pública na Europa e nos Estados Unidos. Oeiras: Celta.

Goss, Mary (1963), "Patterns of bureaucracy among hospital physicians", in Elliot Freidson (org.), The Hospital in Modern Society. New York: The Free Press.

Gruening, Gernod (2001), “Origin and theoretical basis of New Public Management”, International Public Management Journal, 4, 1-25.

Lister, Ruth (2001), “Towards a Citizens' Welfare State: The $3+2$ 'R's of Welfare Reform”, Theory, Culture \& Society, 18(2-3), 91-111. 
Mechanic, David; Rochefort, David (1996), “Comparative Medical Systems”, Annual Review of Sociology, 22, 239-270.

Ministério da Saúde (1988a), "Decreto-Lei n. ${ }^{\circ}$ 19/88”, Diário da República, n. ${ }^{\circ}$ 17, 3. ' Suplemento, Série I, 248(20)-248(23).

Ministério da Saúde (1988b), "Decreto Regulamentar n. 3/88”, Diário da República, n. ${ }^{\circ} 18$, Suplemento, Série I, 256(2)-256(11).

Ministério das Finanças (1999), "Decreto-Lei n. ${ }^{\circ}$ 558/99", Diário da República, n. ${ }^{\circ} 292$, Série I-A, 9012-9.

Ministério das Finanças (2001), Relatório do Orçamento do Estado para 2002. Lisboa: Ministério das Finanças.

Ministério das Finanças (2002), Relatório do Orçamento do Estado para 2003. Lisboa: Ministério das Finanças.

Ministério das Finanças (2003), Relatório do Orçamento do Estado para 2004. Lisboa: Ministério das Finanças.

Ministério das Finanças (2004), Relatório do Orçamento do Estado para 2005. Lisboa: Ministério das Finanças.

Ministério das Finanças (2005), Relatório do Orçamento do Estado para 2006. Lisboa: Ministério das Finanças.

Ministério das Finanças (2006), Relatório do Orçamento do Estado para 2007. Lisboa: Ministério das Finanças.

Ministério das Finanças (2007), Relatório do Orçamento do Estado para 2008. Lisboa: Ministério das Finanças.

Ministério das Finanças (2008), Relatório do Orçamento do Estado para 2009. Lisboa: Ministério das Finanças.

Mozzicafreddo, Juan (2002), Estado-Providência e Cidadania em Portugal. Oeiras: Celta.

OECD (1995), Governance in Transition - Public Management Reforms in OECD Countries. Paris: OECD.

OPSS (2009), Relatório de Primavera 2009. 10/30 anos: Razões para Continuar. Lisboa: OPSS.

Peck, Jamie; Tickell, Adam (2002), “Neoliberalizing Space”, Antipode, 34 (3), 380-404. Pollitt, Christopher (1990), Managerialism and the Public Services. Oxford: Blackwell.

Presidência do Conselho de Ministros (2005), "Resolução do Conselho de Ministros n. ${ }^{\circ}$ 124/2005”, Diário da República, n. ${ }^{\circ}$ 149, Série I-B, 4502-4.

Santos, Boaventura de Sousa (1987), "O Estado, a sociedade e as políticas sociais: o caso das políticas de saúde”, Revista Crítica de Ciências Sociais, 23, 13-74.

Santos, Boaventura de Sousa (1992), O Estado e a Sociedade em Portugal (1974-1988). Porto: Edições Afrontamento.

Silva, Pedro Adão e (2002), "O modelo de welfare da Europa do Sul: reflexões sobre a utilidade do conceito”, Sociologia, Problemas e Práticas, 38, 25-59. 
Stoleroff, Alan; Correia, Tiago (2008), “A empresarialização do sector hospitalar público português: a desregulação do mercado de trabalho médico e os desafios sindicais

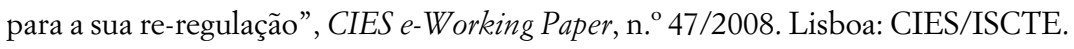
Traynor, Michael (1996), "A literary approach to managerial discourse after the NHS reforms”, Sociology of Health and Illness, 18(3), 315-40. 